\title{
Quantificação e método para seleção de plantas nucelares de Poncirus trifoliata ${ }^{(1)}$
}

\author{
Roberto Pedroso de Oliveira(2), Walkyria Bueno Scivittaro(2) e Elizete Beatriz Radmann ${ }^{(3)}$
}

\begin{abstract}
Resumo - O objetivo deste trabalho foi quantificar a porcentagem de plantas zigóticas e nucelares de Poncirus trifoliata (L.) Raf. em uma população resultante de polinização aberta e avaliar a eficiência de seleção de plantas nucelares com base na morfologia e no vigor. Sementes de frutos maduros foram semeadas em tubetes de $50 \mathrm{~cm}^{3}$, e após 150 dias as plantas foram transplantadas para sacos de plástico. A morfologia foliar e a altura das plantas foram avaliadas 300 dias após a semeadura, e a caracterização genética foi feita por sistemas isoenzimáticos. Em média, obteve-se 1,07 plantas por semente, e o número máximo observado foi de duas plantas por semente. Nesses casos, ambas as plantas foram caracterizadas como nucelares por análise isoenzimática, embora apresentassem tamanho diferenciado e menor do que a média de altura das demais. As plantas zigóticas identificadas, 5,9\% da população, distribuíram-se nas classes de menor altura, manifestando depressão genética. Não foram observadas plantas com vigor híbrido. A diferenciação entre as plantas nucelares e zigóticas, por meio de caracteres morfológicos da folha, não foi possível. O descarte visual das plantas menores, cerca de $30 \%$ da população, é eficiente na seleção de porta-enxertos nucelares de trifoliata produzidos em tubetes em ambiente protegido.
\end{abstract}

Termos para indexação: polinização, isoenzima, heterose, citros.

\section{Quantification and method to select nucellar plants of Poncirus trifoliata}

\begin{abstract}
The aim of this work was to quantify the percentage of zygotic and nucellar plants of Poncirus trifoliata (L.) Raf. in an open pollinated population, and to evaluate the efficiency of the morphology and vigor-based selection method of nucellar plants. Seeds from mature fruits were sowed in plastic tubes of $50 \mathrm{~cm}^{3}$. After 150 days the plants were transferred to plastic bags of 4,8 $\mathrm{dm}^{3}$. Leaf morphology and height of plants were evaluated 300 days after sowing. Genetic characterization was carried out by isoenzymatic systems. In average, 1.07 plants were obtained per seed and the maximum value was two plants per seed. In these cases, both plants were characterized as nucellar by isoenzymes, although showing different and smaller size than the average of the rest of the plants. Zygotic plants identified were $5.9 \%$ of the population and were distributed in the classes of smaller size, showing genetic depression. Plants showing hybrid vigor were not observed. The differentiation of nucellar from zygotic plants was not possible by leaf morphological characters. The visual elimination of the smaller plants, about $30 \%$ of the population, is an efficient method to select trifoliata nucellar plants produced in plastic tubes under protected environment.
\end{abstract}

Index terms: pollination, isoenzymes, heterosis, citrus.

\footnotetext{
(1) Aceito para publicação em 14 de agosto de 2003.

(2) Embrapa-Centro de Pesquisa Agropecuária de Clima Temperado (CPACT), Caixa Postal 403, CEP 96001-970 Pelotas, RS. Bolsista do CNPq. E-mail rpedroso@cpact.embrapa.br, wbscivit@cpact.embrapa.br

(3) Embrapa-CPACT. Bolsista do DTI-CNPq. E-mail: eradmann@hotmail.com
}

\section{Introdução}

A citricultura é uma das atividades agrícolas de maior importância econômica no Brasil, com produção comercial em praticamente todos os Estados (Brasil, 2000).

Os citros são propagados por enxertia de borbulhas em porta-enxertos produzidos por meio de semen- 
tes. O porta-enxerto desempenha um papel determinante na performance, porte e longevidade das plantas, na tolerância às doenças, na produção e na qualidade da fruta (Soost \& Cameron, 1975).

O porta-enxerto mais utilizado no Sul do Brasil, especialmente no Estado do Rio Grande do Sul, é o trifoliata, Poncirus trifoliata (L.) Raf., porque apresenta tolerância ao frio, menor porte da planta e alta qualidade da fruta (Herrero et al., 1996), além de resistência ao vírus-da-tristeza, à gomose de Phytophthora e ao nematóide Tylenchulus semipenetrans (Castle, 1987).

Os gêneros Poncirus e Citrus pertencem à subtribo Citrinae, podendo haver autofecundação e cruzamento natural entre espécies com produção de descendentes férteis (Swingle \& Reece, 1967). Em razão das sementes serem poliembriônicas, as plântulas de Poncirus, assim como as de Citrus, podem ser zigóticas (sexuais) ou nucelares (apomíticas) quanto à sua origem. A proporção de plântulas zigóticas e nucelares varia em função do genótipo e das condições ambientais (Soost \& Cameron, 1975). Na produção comercial de mudas de citros, busca-se selecionar os embriões nucelares por serem geneticamente idênticos à planta-mãe e descartar os zigóticos por comprometerem a uniformidade dos tratos culturais e a produtividade (Roose \& Traugh, 1988).

Na prática, durante a formação dos porta-enxertos, os viveiristas tentam selecionar as plantas nucelares com base na morfologia das folhas e no vigor das plantas. No entanto, a eficiência desse método é pouco conhecida quanto ao trifoliata, principalmente quando as mudas são produzidas em ambiente protegido.

Vários métodos podem ser utilizados para confirmar a natureza zigótica ou nucelar das plantas, destacando-se o uso de isoenzimas por ser um método relativamente simples e de baixo custo (Khan \& Roose, 1988; Ollitrault et al., 1992).

O objetivo deste trabalho foi quantificar a porcentagem de plantas zigóticas e nucelares de Poncirus trifoliata (L.) Raf. em uma população resultante de polinização aberta e avaliar a eficiência do método de seleção de plantas nucelares com base na morfologia foliar e no vigor.

\section{Material e Métodos}

O experimento foi conduzido em viveiro telado, nas condições ambientais de Pelotas, RS. As sementes foram extraídas de frutos maduros de Poncirus trifoliata (L.) Raf. seleção Davis A, cujas plantas encontravam-se circundadas por outras espécies de citros. A semeadura foi realizada a $3 \mathrm{~cm}$ de profundidade, em tubetes de $50 \mathrm{~cm}^{3}$ contendo substrato comercial a base de casca de Pinus, sendo empregada uma semente por tubete. Utilizaram-se 150 repetições. Após 150 dias, foram escolhidos, ao acaso, 110 tubetes, e foi avaliado o número de plantas existente em cada recipiente. Essas plantas foram numeradas e transplantadas para sacos de plástico de $4,8 \mathrm{dm}^{3}$ contendo o mesmo substrato, sendo, sempre, conduzidas em haste única. Aos 300 dias após a semeadura, foi realizada a avaliação da morfologia das folhas e da altura das plantas.

A caracterização genética foi realizada utilizando-se nove sistemas isoenzimáticos: esterase (EST), fosfatase ácida (APS), fosfoglucomutase (PGM), 6-fosfogluconato desidrogenase (6-PGDH), glutamato oxaloacetato transaminase (GOT), isocitrato desidrogenase (IDH), leucina aminopeptidase (LAP), malato desidrogenase (MDH) e xikimato desidrogenase (SKDH).

$\mathrm{Na}$ análise de isoenzimas, as folhas maduras de todas as plantas foram lavadas em água corrente, mergulhadas em água destilada e secadas em papel toalha. As amostras, compostas por $10 \mathrm{mg}$ de folha, foram transferidas para placas de porcelana com sulcos arredondados, onde foram mantidas sobre cubos de gelo. Em seguida, foi feita a maceração com bastão de vidro esmerilhado na presença de tampões específicos. Para a extração, utilizou-se tampão composto por histidina pH 6,5 com solução de mercaptoetanol a $0,15 \%$, na proporção $1: 2$, para os sistemas APS, GOT, 6-PGDH, IDH, LAP, MDH, PGM e SKDH, e o tampão proposto por Scandalios (1969), com pH 8,3, mais solução de mercaptoetanol a $0,15 \%$, na proporção 1:1, para o sistema EST.

Após a extração, foi feita a embebição do extrato com papel Wattmann 3MM e aplicação em orifícios de 1,5 x 4,0 mm, feitos com auxílio de pente de aço inoxidável em géis de poliacrilamida. A eletroforese foi realizada em sistema horizontal, utilizando tampão de Shields et al. (1983) e géis de poliacrilamida a 5\% para os sistemas 6-PGDH, IDH, MDH, PGM e SKDH, e tampão de Scandalios (1969) e géis de poliacrilamida a 6\% para LAP, APS e GOT e 5\% para EST. As migrações eletroforéticas foram realizadas em câmara fria a uma temperatura média de $4^{\circ} \mathrm{C}$. A diferença de potencial foi mantida em torno de $10 \mathrm{~V} \mathrm{~cm}^{-1}$, interrompendo-se a corrente elétrica quando o fronte, marcado pelo azul de bromofenol, atingiu $9 \mathrm{~cm}$ do ponto de aplicação. 
Para revelação histoquímica, foram utilizados métodos descritos por Scandalios (1969) para APS, EST e LAP; Vallejos (1983) para IDH, 6-PGDH, PGM e SKDH; e Ayala et al. (1972) para GOT e MDH. Os géis foram mantidos em estufa a $37^{\circ} \mathrm{C}$, até o aparecimento das bandas. A fixação foi realizada em solução composta por água destilada, metanol e ácido acético, na proporção 5:5:1.

A interpretação dos resultados foi feita considerandose a mobilidade relativa das bandas, selecionando-se somente as bandas consistentes e estáveis.

\section{Resultados e Discussão}

A porcentagem de tubetes em que ocorreu o desenvolvimento de somente uma planta de trifoliata foi de $92,7 \%$. Este valor é considerado elevado, em razão do nível acentuado de poliembrionia da cultivar. Khan \& Roose (1988) e Moore \& Castle (1988) obtiveram resultados semelhantes para trifoliata, respectivamente $90 \%$ e $86 \%$. Segundo Frost \& Soost (1968), as cultivares poliembriônicas apresentam uma grande variação quanto ao número de embriões que se desenvolvem por semente. A média obtida, no presente trabalho, foi de 1,07 plantas/semente, atingindo o número máximo de duas plantas. Outras espécies de porta-enxertos de citros apresentam valores médios superiores a dois (Moore \& Castle, 1988).

Nos oito casos em que houve desenvolvimento de duas plantas a partir de uma mesma semente, notou-se um diferencial acentuado no tamanho das plantas. Em função da genética do Poncirus, era esperado que a planta maior fosse de natureza nucelar e a menor zigótica, ocorrendo, nesta última, depressão genética (Cameron \& Frost, 1968). Porém, as análises com isoenzimas revelaram a natureza nucelar de ambas em todos os casos estudados. O crescimento diferenciado deve ter ocorrido, provavelmente, em razão da posição favorável à germinação de determinado embrião nucelar ou ao maior tamanho de um deles (Frost \& Soost, 1968).

A análise com os sistemas isoenzimáticos utilizados revelou a presença de sete plantas zigóticas, ou seja, 5,9\% da população. Ashari et al. (1988) obtiveram 2,6\% e Roose \& Traugh (1988) 18\% com a mesma seleção. As condições edafoclimáticas e as espécies polinizadoras apresentam grande influência na ocorrência de plantas zigóticas (Soost \& Cameron, 1975). O tamanho reduzido do tubete $\left(50 \mathrm{~cm}^{3}\right)$ e a forma adensada com que foram dispostos em suportes metálicos, gerando competição por luz e nutrientes, pode ter contribuído para a inibição da germinação de outros embriões.

As plantas zigóticas podem ter se originado por autopolinização, cruzamento com outras plantas de trifoliata ou mesmo com espécies de Citrus (Swingle \& Reece, 1967). Segundo Khan \& Roose (1988), a probabilidade das plantas zigóticas obtidas terem sido originárias de espécies de Citrus é baixa, em função da trifoliata florescer 20 a 30 dias antes. Em condições de polinização aberta, como ocorreu no presente trabalho, esses autores verificaram que a maioria das plantas zigóticas foi proveniente de autopolinização e polinização por outras plantas de trifoliata. A ausência de distância genética entre os parentais pode ter sido uma das causas da baixa porcentagem de plantas zigóticas obtida, por aumentar significativamente a probabilidade de depressão genética pela manifestação de genes deletérios recessivos em homozigose nas plantas zigóticas (Cameron \& Frost, 1968).

A eficiência do uso de sistemas isoenzimáticos na separação de plantas nucelares e zigóticas de trifoliata é bastante conhecida (Roose \& Traugh, 1988), principalmente por se tratar de um marcador co-dominante e do nível de heterozigosidade do Poncirus trifoliata (Federici et al., 1998). Porém, não se pode descartar a probabilidade da existência de mais plantas zigóticas na população. Os sistemas APS, EST, PGM, IDH, LAP, 6-PGDH e SKDH não apresentaram polimorfismo nas plantas analisadas, enquanto os sistemas GOT e MDH proporcionaram a identificação de cinco plantas zigóticas cada um, sendo que, em ambos os casos, duas plantas zigóticas foram identificadas por um só sistema (Figura 1).

A diferenciação das plantas nucelares e zigóticas não pôde ser obtida por meio da morfologia foliar. Khan \& Roose (1988) também não obtiveram êxito utilizando este caráter para a trifoliata. Todas as plantas zigóticas apresentaram folha trifoliolada, o que era esperado pelo fato de o caráter ser regulado por um gene dominante (Frost \& Soost, 1968).

Não houve distribuição normal dos dados em razão da existência das classes de 30,5 cm a 95,3 cm, em que se encontraram todas as plantas zigóticas identificadas (Figura 2). A altura das plantas zigóticas 
foi de $51,5 \mathrm{~cm}, 60,5 \mathrm{~cm}, 71,8 \mathrm{~cm}, 86,0 \mathrm{~cm}$ e $87,8 \mathrm{~cm}$, e duas delas morreram. A importância da seleção dos porta-enxertos é conhecida desde que Webber (1932)
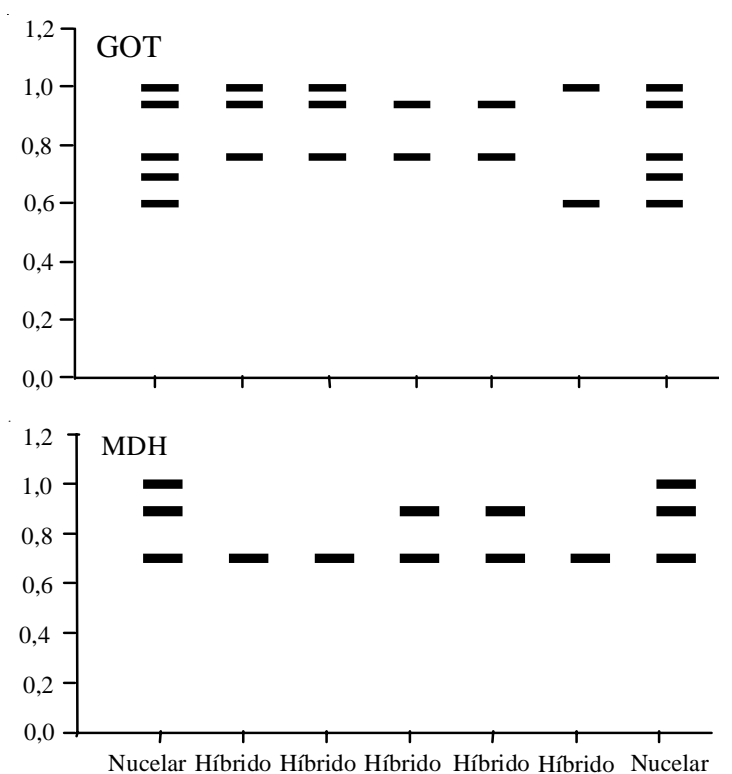

Figura 1. Representação dos padrões isoenzimáticos obtidos com glutamato oxaloacetato transaminase (GOT) e com malato desidrogenase (MDH) em plantas nucelares e zigóticas de trifoliata.

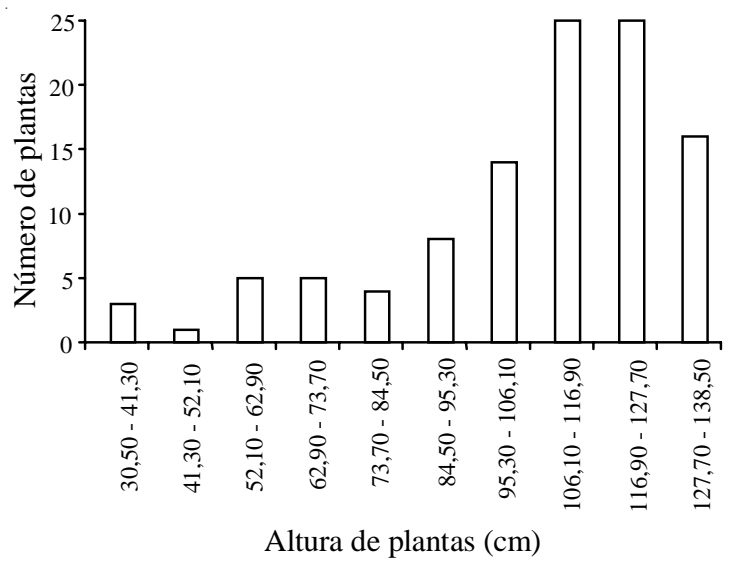

Figura 2. Distribuição de freqüências de plantas nucelares e zigóticas de trifoliata em razão da altura, 300 dias após a semeadura. demonstrou que plantas de laranja 'Valencia' enxertadas sobre plantas zigóticas eram menos vigorosas que aquelas em porta-enxerto de origem nucelar. Desde então, a seleção vem sendo realizada nos viveiros comerciais, eliminando-se as plantas menos vigorosas (Moore \& Castle, 1988).

Os resultados confirmam a aplicação deste método prático de seleção também para porta-enxertos de trifoliata produzidos em tubetes em ambiente protegido, sendo recomendada a eliminação de cerca de $30 \%$ das plantas. Isto é bastante importante para o produtor, pois avaliações realizadas por Khan \& Roose (1988) demonstraram que, em média, as plantas zigóticas de trifoliata produzem $11 \%$ a menos do que as nucelares. Deve-se, também, ressaltar que na população não foram encontradas plantas zigóticas manifestando vigor híbrido, como verificado em cruzamentos de Citrus grandis x Poncirus trifoliata e de (C. sinensis x C. paradisi) x P. trifoliata (Cameron $\&$ Frost, 1968).

\section{Conclusões}

1. A maioria das sementes de Poncirus trifoliata originam apenas uma planta, a despeito do grau de poliembrionia, sendo de origem nucelar.

2. A porcentagem de plantas zigóticas de P. trifoliata, obtidas de sementes de árvores com polinização aberta, é baixa (5,9\%).

3. A identificação de plantas zigóticas pode ser realizada mediante o uso de marcadores isoenzimáticos, porém não se recomenda o uso de caracteres foliares com essa finalidade.

4. As plantas zigóticas encontram-se entre as de menor altura na população, podendo ser descartadas pela eliminação de 30\% das plantas menores.

\section{Referências}

ASHARI, S.; ASPINALL, D.; SEDGLEY, M. Discrimination of zygotic and nucellar seedlings of five polyembrionic citrus rootstocks by isozyme analysis and seedling morphology. Journal of Horticultural Science, Ashford, v. 63, n. 4, p. 695-703, 1988.

AYALA, F. J.; POWEL, J. R.; TRACEY, M. L.; MOURÃO, A. C.; PEREZ-SALAS, S. Enzyme variability in the Drosophila willistoni group - IV: genic variation in 
natural populations of Drosophila willistoni. Genetics, Oxford, v. 70, p. 113-139, 1972.

BRASIL. Ministério da Agricultura e do Abastecimento. Mapeamento da fruticultura brasileira. Brasília, 2000. $110 \mathrm{p}$.

CAMERON, J. W.; FROST, H. B. Genetics, breeding and nucellar embryony. In: REUTHER, W.; BATCHELOR, L. D.; WEBBER, H. J. (Ed.). The citrus industry. Berkeley: University of California Press, 1968. v. 2, p. 325-370.

CASTLE, W. S. Citrus rootstocks. In: ROM, R. C.; CARLSON, R. F. (Ed.). Rootstocks for fruit crops. New York: Wiley, 1987. p. 361-399.

FEDERICI, C. T.; FANG, D. Q.; SCORA, R. W.; ROOSE, M. L. Phylogenetic relationships within the genus Citrus (Rutaceae) and related genera as revealed by RFLP and RAPD analysis. Theoretical and Applied Genetics, Berlin, v. 96, p. 812-822, 1998.

FROST, H. B.; SOOST, R. K. Seed reproduction; development of gametes and embryos. In: REUTHER, W.; BATCHELOR, L. D.; WEBBER, H. J. (Ed.). The citrus industry. Berkeley: University of California Press, 1968. v. 2, p. 290-324.

HERRERO, R.; ASÍNS, M. J.; CARBONELL, E. A.; NAVARRO, L. Genetic diversity in the orange subfamily Aurantioideae - I: intraspecies and intragenus genetic variability. Theoretical and Applied Genetics, Berlin, v. 92, p. 599-606, 1996.

KHAN, I. A.; ROOSE, M. L. Frequency and characteristics of nucellar and zygotic seedlings in three cultivars of trifoliate orange. Journal of the American Society for Horticultural Science, Mount Vernon, v. 113, p. 105-110, 1988.

MOORE, G. A.; CASTLE, W. S. Morphological and isozymic analysis of open-pollinated citrus rootstocks populations. Journal of Heredity, Washington, v. 79, p. 59-63, 1988.
OLLITRAULT, P.; FAURE, X.; NORMAND, F. Citrus rootstocks characterization with bark and leaf isozymes application to screen zygotic and nucellar trees. In: INTERNATIONAL CITRUS CONGRESS, 7., 1992, Acireae. Proceedings... Acireae: International Citrus Society, 1992. v. 1. p. 338-341.

ROOSE, M. L.; TRAUGH, S. N. Identification and performance of citrus trees on nucellar and zygotic rootstocks. Journal of the American Society for Horticultural Science, Mount Vernon, v. 113, p. 100105, 1988.

SCANDALIOS, J. G. Genetic control of multiple molecular forms of enzymes in plants: a review. Biochemical Genetics, New York, v. 3, p. 37-39, 1969.

SHIELDS, C. R.; ORTON, T. J.; STUBBER, C. W. An outline of general resource needs and procedures for the electrophoretic separation of active enzymes from plant tissue. In: TANKSLEY, S. D.; ORTON, T. J. (Ed.). Isozymes in plant genetics and breeding. Amsterdam: Elsevier, 1983. p. 443-468.

SOOST, R. K.; CAMERON, J. W. Citrus. In: JANICK, J.; MOORE, J. N. (Ed.). Advances in fruit breeding. West Lafayette: Purdue University Press, 1975. p. 507540.

SWINGLE, W. T.; REECE, P. C. The botany of citrus and its wild relatives. In: REUTHER, W.; WEBBER, H. J.; BATCHELOR, L. D. (Ed.). The citrus industry. Berkeley: University of California Press, 1967. v. 1, p. 190-430.

VALLEJOS, C. E. Enzyme activity staining. In: TANKSLEY, S. D.; ORTON, T. J. (Ed.). Isozymes in plant genetics and breeding. Amsterdam: Elsevier, 1983. pt. A, p. 469-515.

WEBBER, H. J. Variations in citrus seedlings and their relation to rootstocks selection. Hilgardia, Berkeley, v. 7, p. 1-79, 1932. 